\title{
Experimental rat models of chronic allograft nephropathy: a review
}

This article was published in the following Dove Press journal: International Journal of Nephrology and Renovascular Disease 23 July 2014

Number of times this article has been viewed

\author{
Badri Shrestha \\ John Haylor \\ Sheffield Kidney Institute, \\ Sheffield Teaching Hospitals \\ NHS Trust, Sheffield, UK
}

Correspondence: Badri Shrestha Sheffield Kidney Institute, Sheffield Teaching Hospitals NHS Trust, Sheffield S5 7AU, UK

Tel +44 I I 42434343

Fax +44 I | 427| 4604

Email shresthabm@doctors.net.uk
Abstract: Chronic allograft nephropathy (CAN) is the leading cause of late allograft loss after renal transplantation (RT), which continues to remain an unresolved problem. A rat model of CAN was first described in 1969 by White et al. Although the rat model of RT can be technically challenging, it is attractive because the pathogenesis of CAN is similar to that following human RT and the pathological features of CAN develop within months as compared with years in human RT. The rat model of RT is considered as a useful investigational tool in the field of experimental transplantation research. We have reviewed the literature on studies of rat RT reporting the donor and recipient strain combinations that have investigated resultant survival and histological outcomes. Several different combinations of inbred and outbred rat combinations have been reported to investigate the multiple aspects of transplantation, including acute rejection, cellular and humoral rejection mechanisms and their treatments, CAN, and potential targets for its prevention.

Keywords: interventions, therapy, late allograft loss, renal transplantation

\section{Introduction}

Despite the advances in immunosuppressive agents, chronic allograft nephropathy (CAN) remains the leading cause of late allograft loss following renal transplantation (RT). ${ }^{1}$ Experimental research has been undertaken in animal models to understand the pathogenesis and molecular biology of CAN and to identify potential therapeutic targets for its prevention and treatment. ${ }^{2,3}$

In humans, CAN develops slowly over months and years before being fully established. In rat models of CAN, impairment of renal function and histopathology similar to that described in humans can be produced in a few months, allowing investigators to study its pathology within a reasonable period of time. The factors implicated in the pathogenesis of CAN in the rat mimic the pathogenesis of CAN in human clinical RT; particularly to RT from a live kidney donor source, since the coldischemia time is short in both situations. Thus, the rat provides an important model of RT in which to study the pathology and potential treatment of CAN. ${ }^{4}$ The aim of this paper is to review the published literature on the models of CAN and to explore their advantages and disadvantages and the interventions undertaken.

\section{Literature search}

The literature search was carried out in PubMed and relevant websites using the words "renal transplantation", "chronic allograft nephropathy", "rat", "animals", "transplant fibrosis", and "prevention". Relevant references were compiled in the 
EndNote (X6.0.1, Bld 6599; Thomson Reuters, New York, NY, USA) software.

\section{Advantages of rat models}

RT techniques have been described in pigs, dogs, rabbits, rats, and mice. ${ }^{5-9}$ Compared with larger animals, the advantages of using the rat include 1) improved longterm survival of renal transplants due to the use of inbred strains, 2) lower cost of experimental animals, 3) simple animal maintenance which does not require sophisticated facilities, 4) less critical requirement for aseptic surgery, and 5) well established techniques of vascular and ureteric anastomoses for RT. ${ }^{10,11}$

\section{Strains of rats}

The first description of RT in rats was presented by Bernard Fisher and Sun Lee at the American College of Surgeons Meeting in Chicago in 1961 and subsequently published in 1965. ${ }^{8,12}$ RT was performed using inbred Lewis (LEW) rats, and therefore no immunosuppressive regimens were required. In subsequent studies, the following rat strains were used as either donor or recipient: Fisher 344 (inbred ( $\left.{ }^{\mathrm{In}}\right)$ ), Sprague Dawley (SD) (outbred ( $\left.{ }^{\mathrm{Ou}}\right)$ ), Wistar Furth (WF) (outbred $\left.\left({ }^{\mathrm{Ou}}\right)\right)$, LEW (inbred $\left({ }^{\mathrm{In}}\right)$ ), brown Norway $(\mathrm{BN})$ (inbred $\left({ }^{\mathrm{In}}\right)$ ), and Dark Agouti (DA) (inbred $\left({ }^{(n)}\right)$ ). Either inbred or outbred strains may be used depending upon the aim of the individual study. ${ }^{10,13-23}$

The following combinations such as Fisher 344-toLEW, DA-to-BN, DA-to-WF, DA-to-LEW, SD-to-WF, and LEW to-BN have been used to induce CAN, with both advantages and disadvantages to each model. ${ }^{23-33}$ However, since the Fisher 344-to-LEW model of RT is the most commonly employed in experimental studies, the establishment and application of this combination is described in detail.

\section{Fisher 344-to-LEW model of CAN Establishment of the model}

White and Mullen ${ }^{34}$ described in 1969 for the first time RT using the Fisher 344 (F344) rat as donor and the LEW rat as recipient to produce a model of chronic rejection. Although the LEW-to-LEW isograft maintains relatively well preserved renal function, F344 allografts develop clinical and histopathological features of CAN within a few weeks to months after RT. ${ }^{35}$ Paul et al ${ }^{39}$ demonstrated that RT between F344to-LEW rats survives spontaneously, without the use of immunosuppressive drugs. The F344-to-LEW model is useful because the rat strains differ partially at major histocompatibility complex (MHC) (class I and class II) and various
non-MHC loci, thereby making a weakly histocompatible combination that allows RT without immunosuppression, which cannot be done in humans. LEW rats receiving an F344 graft develop raised glomerular pressure and proteinuria after 1 week post-RT, which gradually evolves into CAN ${ }^{36}$ The histological changes occur predominantly in the glomeruli showing mesangial expansion, glomerular fibrosis, intimal thickening of blood vessels, dilatation of capillaries, splitting of capillary basement membrane, and deposition of eosinophilic materials in capillary loops. Classical changes of CAN in the vascular and tubulointerstitium occur simultaneously or later, but similar to lesions seen in human RT. ${ }^{12}$ Vass et $\mathrm{al}^{37}$ observed marked increase in the number of perivascular and interstitial lymphatic vessels in the allografts, which correlated with the extent of interstitial fibrosis.

The same investigators also demonstrated that LEW rats with long-standing F344 RT produce antibodies against both glomerular and tubular basement membranes. ${ }^{38}$ Subsequently, antibodies directed against mesangial and endothelial cells have been detected in the sera of the allografts with long-standing RTs. Western blot analysis, followed by immunoprecipitation, has identified the antibody-binding sites on mesangial cells to be biglycan and decorin. ${ }^{39}$ It is recognized that both biglycan and decorin appear to play roles in the tissue repair process and bind transforming growth factor (TGF)- $\beta$, a profibrotic cytokine which may play a major role in CAN. Antibodies binding to biglycan and decorin appear to have the effect of generating more "free" TGF- $\beta$ to interact with its receptors and interfere with the stimulation of matrix metalloproteases. TGF- $\beta$ inhibits the proliferation of mesangial cells and may play a role in renal fibrosis by stimulating mesangial cells to produce matrix proteins. Fibroblasts are also stimulated by TGF- $\beta$ to produce matrix protein. ${ }^{40}$

In CAN, the alteration of the extracellular matrix compartment and proliferation of various cell types are regulated by the metzincin superfamily of metallo-endopeptidases, including matrix metalloproteinases (MMPs), a disintegrin and metalloproteinase (ADAM) and meprin. Berthier et $\mathrm{al}^{41}$ observed that members of metzincin families (MMP, ADAM, and meprin) and of tissue inhibitors of metalloproteinase (TIMPs) are differentially regulated in CAN in the F344-toLEW model. Messenger ribonucleic acid (mRNA) levels of MMPs (MMP-2/-11/-12/-14), their inhibitors (TIMP-1/-2), ADAM-17, and TGF- $\beta 1$ significantly increase in CAN. In contrast, mRNA levels of MMP-9/-24 and meprin $\alpha / \beta$ downregulate significantly. ${ }^{41,42}$ 


\section{Cyclosporin}

Diamond et $\mathrm{a}^{24}$ from Boston, USA, used cyclosporin $(5 \mathrm{mg} / \mathrm{kg} /$ day $)$ for the first 10 days post-RT to prevent acute rejection and studied the changes in renal function, morphology, and immunohistology between F344-to-LEW allografts and LEW-to-LEW isografts over the course of 24 weeks. A higher urine albumin excretion was demonstrated in the allografts as early as 4 weeks after RT, which rose dramatically by 20 weeks. Serum creatinine was elevated in allografts after 16 weeks, while renal blood flow and glomerular filtration rate (GFR) measured by $p$-aminohippurate and inulin clearances, respectively, were significantly lower in the allografts at 24 weeks. The frequency of glomerulosclerotic lesions was significantly increased in allografts and correlated with albumin excretion. There was significantly greater infiltration of the glomeruli with cluster of differentiation $(\mathrm{CD}) 8^{+}$and pan-T-cells in the allografts. ${ }^{24}$ Grenz et al ${ }^{43}$ demonstrated significant improvement in GFR in the same model when theophylline was given $(10 \mathrm{mg} / \mathrm{kg}$, subcutaneously) (GFR of allografts $0.23 \pm 0.05 \mathrm{~mL} / \mathrm{min} / \mathrm{g}$ kidney weight $[\mathrm{n}=10]$ compared with $0.50 \pm 0.09 \mathrm{~mL} / \mathrm{min} / \mathrm{g}$ in rats receiving theophylline $[\mathrm{n}=9, P<0.01])$ without affecting the interstitial infiltration of the graft by monocytes/macrophages and T-cells. Likewise, serum cytokines interleukin (IL)-2, IL-6, IL-10, tumor necrosis factor (TNF)- $\alpha$, and erythropoietin plasma levels were not different among the allograft groups ${ }^{43}$ In both studies, cyclosporin given for the first 10 days prevented acute rejection and allowed development of CAN in the allografts.

\section{Alloantibodies, cytokines, and adhesion molecules}

Hancock et $\mathrm{al}^{44}$ from Boston examined the host immune mechanisms responsible for the initiation and progression of chronic rejection in the same model. Peak levels of immunoglobulin (Ig)M and IgG alloantibodies were demonstrated at 2-4 weeks by flow cytometry, with a gradual decline to baseline thereafter. Immunohistology showed early and progressive deposition of $\operatorname{IgM}, \operatorname{IgG}, \mathrm{C} 3$, and fibrin in the vessel walls and glomeruli. In addition, by 12 weeks, extensive infiltration by activated IL-2 receptor positive (IL-2R+) macrophages and $\mathrm{CD} 4^{+} \mathrm{T}$-cells could be demonstrated in the glomeruli and blood vessels, in conjunction with staining for cytokines such as TNF- $\alpha$, IL-1, and IL-6. The persistent and dense intraglomerular expression of IL-6 indicated its potent mitogenic effect on mesangial cells leading to glomerulosclerosis.

There was also increased expression of intercellular adhesion molecule-1 (ICAM-1) in the graft vascular endothelium, which peaked at 16 weeks and showed increased binding in vitro to naïve host lymphocytes. ${ }^{44}$ The authors concluded that an antibody-mediated host response followed by a cellular response was responsible for the release of cytokine production and upregulation of adhesion molecules which induced the scarring process leading to graft loss.

\section{Prevention of chronic rejection Manipulation of the cellular immune response}

Several experiments have been carried out in the F344-LEW model to abrogate the alloantigen-driven histological and immunological events in order to delay or prevent alloantigen recognition. T-cell activation requires two steps: namely, binding of T-cell receptor to the antigen presented by the antigenpresenting cells (APCs) (signal 1) followed by co-stimulation (signal 2) through binding of CD28 molecule of the T-cell to CD80 (B7-1) and CD86 (B7-2) on the APC. Blockade of the co-stimulation pathway (CD28-B7) produces a state of anergy, a failure of T-cell activation, which is also produced by CD152 (cytotoxic T-lymphocyte antigen-4; CTLA-4) combined with CD28 and CD86. Alternatively, CD40 ligand on T-cells can combine with CD40 on the APC to initiate the co-stimulation signal leading to activation of these cells.

Blockade of the co-stimulation pathway by the infusion of CTLA-4-immunoglobulin, which binds to B7 molecules on the surface of the APC, leads to significant reduction of proteinuria, glomerulosclerosis, intimal hyperplasia, and mononuclear cellular infiltration. ${ }^{45}$ Similarly, administration of an anti-CD28 monoclonal antibody significantly preserves graft morphology and recipient survival in this model by blocking the T-cell co-stimulation pathway. ${ }^{46}$

\section{Blockade of chemokines}

Chemokines are a family of small-size $(8-10 \mathrm{kDa})$ chemotactic cytokines which, in transplantation, induce the recruitment and activation of T-cells and monocytes or macrophages. So far, more than 50 chemokines and 20 chemokine receptors have been identified. Members of the chemokine family are divided into four groups $(\mathrm{C}, \mathrm{CC}, \mathrm{CXC}$, and $\mathrm{CX} 3 \mathrm{C})$ based upon the position of their first two cysteine residues. They are further classified as inflammatory or hemostatic.

In F344-to-LEW rat allografts, BX-471, a chemokine receptor type 1 (CCR1) antagonist, prevents the infiltration of T-cells and macrophages, decreases cell proliferation (ED1, CD8, and Ki67), and reduces expression of acute phase reactive proinflammatory genes (heme oxygenase-1, osteopontin) and molecules associated with fibrosis (plasminogen activator inhibitor-1, TGF- $\beta$, and biglycan). 
There is a significantly lower number of smooth muscle actin-positive interstitial myofibroblasts and a reduction in the deposition of collagen. ${ }^{47}$

Similarly, Met-RANTES (Regulated on Activation, Normal T-cell Expressed), a chemokine receptor antagonist (CCR5), blocks the effects of RANTES in F344-to-LEW allografts, reducing the infiltration of lymphocytes and macrophages, accompanied by decreased mRNA expression of IL-2, IL-1 $\beta$, TNF- $\alpha$, and RANTES resulting in reduced glomerulosclerosis, tubulointerstitial fibrosis, and proteinuria. $^{48}$

\section{Immunosuppressive agents}

Immunosuppressive drugs have reduced the incidence of acute rejection and improved graft survival. However, the majority are associated with side effects such as the nephrotoxicity of calcineurin inhibitors (CNIs), which are known to contribute to the development of CAN. ${ }^{49}$ Mycophenolate mofetil (MMF), in contrast, acts by inhibiting de novo DNA synthesis, cell surface molecule expression, and antibody production. MMF reduces CAN and improves allograft survival when given immediately or 8 weeks after RT. ${ }^{50}$ In the same model, Luo et $\mathrm{al}^{51}$ examined the effects of tacrolimus with MMF on renal fibrosis and observed progressive deterioration of renal function and CAN morphology in the vehicle and tacrolimus groups, while serum creatinine and inflammatory infiltration (Banff score) showed a significant decrease in the MMF group after 8 weeks posttransplantation compared with those in the other groups. Furthermore, expression levels of connective tissue growth factor and $\alpha$-smooth muscle actin in the MMF group were significantly reduced, and the downregulated expression of E-cadherin was abated. ${ }^{51}$

Sirolimus and its derivative, everolimus, significantly reduce infiltration of the allograft with macrophages and lymphocytes and reduce expression of TGF- $\beta$, ICAM-1, and VCAM (vascular cell adhesion molecule)-1, reducing interstitial fibrosis and tubular atrophy (TA) and prolonging allograft survival. ${ }^{52-54}$

Ko et $a 1,{ }^{55}$ in the same model, observed greater protection against vasculopathy in the sirolimus-treated group, but sirolimus induced proteinuria. The effects were likely to be related to inhibition of vascular endothelial growth factor signaling. ${ }^{55}$ In the same model, Luo et al ${ }^{51}$ concluded that sirolimus ameliorated fibrogenesis in kidney allografts by inhibiting the epithelial mesenchymal transition (EMT) process, whereas cyclosporine did not have this effect.

\section{Oxidative stress}

Oxidative stress is increased in the F344-LEW rat transplant model and is associated with EMT and chronic interstitial fibrosis. Nicotinamide adenine dinucleotide phosphate (NADPH) oxidase (Nox) is an important source of reactive oxygen species generation in the kidney. Inhibition of NADPH-2 (Nox-2) by diphenyleneiodonium or apocynin reduces fibronectin and phosphor-Smad2 and increases E-cadherin levels, thereby inhibiting EMT and fibrogenesis. ${ }^{56}$ In the same model, L-arginine decreases proteinuria and glomerulosclerosis. ${ }^{57}$ However, vitamin E supplementation alone does not prevent CAN. ${ }^{58}$ Both in human $\mathrm{RT}$ recipients and in F344-to-LEW allografts, MMF significantly downregulates Nox-2 activation and EMT through the nuclear factor- $\kappa \mathrm{B}$ pathway in tubular epithelial cells. ${ }^{59}$

\section{Angiotensin antagonists}

Angiotensin II increases the expression of cytokines and adhesion molecules thereby stimulating the synthesis of extracellular matrix and increasing glomerular capillary pressure. Administration of an angiotensin converting enzyme inhibitor (trandolapril) or angiotensin II receptor blocker (losartan) in this model leads to diminished expression of chemokine MCP-1 (monocyte chemoattractant protein-1), preservation of glomerular and tubulointerstitial structures, reduced proteinuria, and improved graft survival. ${ }^{60,61}$ Combination of losartan and MMF completely prevents the development of proteinuria, largely reduces glomerular and tubulointerstitial injury, and suppresses intragraft cell infiltration, thereby producing a better outcome in comparison with transplants receiving a single agent. ${ }^{50}$

\section{Lipid lowering agents}

In the F344-to-LEW renal allograft model, pravastatin reduces macrophage and T-cell graft infiltration and decreases intragraft expression of TGF- $\beta$, causing an attenuation of the recipient anti-donor IgG alloantibodies and upregulation of the anti-apoptotic gene Bag-1. ${ }^{62}$

\section{Mineralocorticoid receptor antagonist agent}

The mineralocorticoid hormone aldosterone is involved in development and/or progression of renal diseases via interaction with a non-epithelial mineralocorticoid receptor (eg, reducing neointima formation). Lahmer et $\mathrm{a}^{63}$ examined the effects of the aldosterone synthase inhibitor fadrozole and the mineralocorticoid receptor antagonist spironolactone compared with vehicle in the F344-to-LEW rat model of CAN. Fadrozole- and spironolactone-treated animals 
demonstrated a higher degree of proteinuria, pathologically elevated potassium values, higher tubulointerstitial damage and glomerulosclerosis, and markedly increased heart weight/bodyweight as compared with vehicle. The positive effects of inhibition of aldosterone as described in cardiac models could not be detected in kidney recipients. ${ }^{63}$

\section{DA-to-BN model of CAN}

DA-to-BN rat model, which requires triple immunosuppression with cyclosporin ( $5 \mathrm{mg} / \mathrm{kg} /$ day), azathioprine ( $2 \mathrm{mg} / \mathrm{kg} /$ day $)$, and methylprednisolone ( $2 \mathrm{mg} / \mathrm{kg} /$ day $)$, has been extensively studied by Soots et al. ${ }^{23}$ This model developed an early acute rejection 5-7 days after RT and chronic rejection within 40-60 days after RT, with chronic allograft damage index (CADI) score of 7.9 \pm 3.1 compared with syngenic transplants, which showed no evidence of acute or chronic rejection (CADI: 1.7 \pm 2.0 ). In the same study, combinations of other strains of rats such as DA-to-albino Oxford and piebaldviral-Glaxo (PVG)-to-BN were examined. The DA-to-albino Oxford combination demonstrated a prolonged acute rejection, but no characteristic chronic changes. The PVG-to-BN combination did not show changes of either acute or chronic rejection. The grafts were monitored with ultrasound-guided fine-needle aspiration cytology. This study concluded that the experimental model of DA-to-BN of RT resembles the CAN seen in human clinical RT. ${ }^{23}$

The same authors have used the DA-to-BN model to demonstrate a significant rise in the collagen/DNA ratio in cytomegalovirus (CMV)-infected grafts compared with uninfected animals, correlating with the development of fibrosis. The expression of type I and III collagen mRNA and presence of myofibroblasts was associated with interstitial fibrosis in CMV-infected grafts. It was concluded that CMV accelerated both atherosclerosis and the development of CAN in rat allograft kidneys. ${ }^{64,65}$ Soots et al ${ }^{66}$ examined the effect of flushing the donor kidney with Euro-Collins ${ }^{\circledR}$ solution (Fresenius Aktiengesellschaft, Oberursel, Germany) containing sodium nitroprusside solution in this model and observed significant reduction in CADI score of TA and interstitial fibrosis with the use of sodium nitroprusside. ${ }^{66}$

\section{DA-to-WF model of CAN}

Yilmaz et $\mathrm{al}^{67}$ studied chronic rejection in the DA-to-WF where the allografts, given cyclosporin $(5 \mathrm{mg} / \mathrm{kg} / \mathrm{day}$, subcutaneously) for 1 week, developed chronic rejection 3 months post-transplantation. Allografts receiving cyclosporin ( $5 \mathrm{mg} / \mathrm{kg} / \mathrm{day}$, subcutaneously) for 12 weeks did not show changes of chronic rejection. In this model, prolonged use of cyclosporin prevented the development of acute rejection. Syngenic DA-to-DA RTs did not show any evidence of chronic rejection. ${ }^{67,68}$ Savikko et al ${ }^{69}$ investigated the role of platelet-derived growth factor (PDGF) in the same model and demonstrated that administration of the imanitib (10 mg/kg/day, orally), a PDGF inhibitor, for the first 30 days after RT completely prevented development of $\mathrm{CAN}$ at 90 days in the treated group. An immunosuppressive drug, FK778, inhibits de novo pyrimidine biosynthesis and several receptor tyrosine kinases. Rintala et $\mathrm{al}^{70}$ investigated its effects on acute and chronic rejection as well as posttransplant PDGF and TGF- $\beta$ expression in combination therapy with CNIs. FK778 in combination with CNIs significantly reduced both early and late PDGF and TGF- $\beta$ expression and development of CAN.

\section{DA-to-LEW model of CAN}

Pascher et al $^{31}$ have described the development of CAN using DA rats as donors to LEW recipients in a variety of immune-modulating models. One model, considered to be a high-responder immunologically, was used in experiments which involved the use of carbon monoxide to reduce immunogenicity and thereby the development of CAN. ${ }^{71}$ Transplanting kidneys from DA to LEW rats, without immunosuppression, leads to death of rats from acute rejection some 7 days after transplantation. ${ }^{72}$ Denecke et al ${ }^{11}$ had examined the effect of low-dose cyclosporine in the same model and observed induction of donor hypo-responsiveness to secondary renal allografts, significantly reduced alloantibody titers in the primary recipients, and dose-dependent and transferable "pro-tolerogenic" effect of low-dose cyclosporine treatment. ${ }^{11}$

\section{SD-to-WF model of CAN}

The SD-to-WF combination is an accelerated model of CAN, where histological evidence of CAN appears as early as 4 weeks post-RT. Teng et $\mathrm{al}^{73}$ examined the expression of the cytoprotective genes A20, heme oxygenase (HO)-1, Bcl-2, and $B c l-X L$ in this model using three different immunosuppressive regimens. All animals received cyclosporin $10 \mathrm{mg} /$ $\mathrm{kg} /$ day for 10 days, but two further groups were maintained on either cyclosporin $6 \mathrm{mg} / \mathrm{kg} /$ day or MMF $20 \mathrm{mg} / \mathrm{kg} /$ day. At the end of 8 weeks, CAN was evident in all groups, but the expression of $A 20$ in grafted kidneys was significantly higher in the MMF than in the cyclosporine group, helping to explain the mechanism by which MMF ameliorates transplant arteriosclerosis in experimental chronic rejection. There was no significant difference between the cyclosporin and the 
MMF groups in the expression of $\mathrm{HO}-1, \mathrm{Bcl}-2$, and $\mathrm{Bcl}-\mathrm{XL} .^{73}$ Similar results were observed when rapamycin was compared with tacrolimus in this model. ${ }^{74}$

Fractalkine is a unique chemokine that functions both as a potent chemoattractant molecule (soluble form) 1 and as an adhesion molecule (membrane anchored form) for cells expressing the fractalkine receptor CX3CR1, such as monocytes, NK (natural killer) cells, and subsets of CD8 ${ }^{+} \mathrm{T}$-cells, involved in chronic transplant arteriosclerosis. Cao et $\mathrm{al}^{32}$ demonstrated increased expression of the fractalkine receptor CX3CR1 in the SD-to-WF model of RT. Fractalkine/ CX3CR1 was mostly expressed in the tubulointerstitium and tubular epithelial cell basolateral membrane. A proportion of the vessel showed positive staining for fractalkine/ CX3CR1, occasionally in glomerular parietal wall cells, was significantly lower in MMF than cyclosporine-treated animals. ${ }^{32}$

\section{LEW-to-BN model of CAN}

Transplanting kidneys from LEW-to-B $\left(\mathrm{RT}^{\mathrm{ln}}\right)$ rats shows interstitial mononuclear cell infiltration, tubulitis, and glomerulitis, in addition to early phase of arteritis at 30 days. By 80 days, TA is seen in $25 \%-50 \%$ and interstitial fibrosis in up to $25 \%$ of renal cortex. There is focal, diffuse, segmental, or globular glomerulosclerosis. In a study by Neto et al, ${ }^{33}$ all recipients had received tacrolimus $(0.5 \mathrm{mg} / \mathrm{kg} /$ day $)$ for 7 days. Cardinal et $\mathrm{al}^{75}$ demonstrated that the administration of molecular hydrogen dissolved in water to this model slowed the progression of CAN, reduced oxidant injury and inflammatory mediator production, and improved overall survival. Inflammatory signaling pathways, such as mitogen-activated protein kinases, were less activated in renal allografts from hydrogen water-treated rats as compared with regular water-treated rats. ${ }^{75}$

\section{WF-to-LEW model of CAN}

Solini et $\mathrm{al}^{76}$ developed a model of CAN using a fully MHC-mismatched rat strain combination, with WF rats as kidney donor and LEW rats as recipients. The two strains differ for class I, class II, and non-MHC genes. Cyclosporin ( $5 \mathrm{mg} / \mathrm{kg} /$ day, intramuscularly) needed to be given for the first 10 days to prevent acute rejection. At 120 days, the allografts developed features of CAN and donor-specific antibodies and chronic antibody-mediated rejection. ${ }^{76} \mathrm{~A}$ few studies have been carried out in this model, which include gene transfer of CTLA-4 Ig into donor kidney, leading to prevention of progressive proteinuria and $\mathrm{CAN}$, and transfer of donor-specific $\mathrm{T}$ helper-2 clones into recipient rats to regulate alloimmune response and prevention of CAN. ${ }^{77,78}$

\section{Conclusion}

We reviewed the relevant published literature that described $\mathrm{RT}$ in rat models of CAN employing combinations of strains and the outcomes of various interventions. We believe that the review will help researchers to understand the application of various rat models of CAN in understanding the molecular mechanisms and development of novel treatments for CAN.

\section{Disclosure}

The authors report no conflicts of interest in this work.

\section{References}

1. Timsit MO, Yuan X, Floerchinger B, Ge X, Tullius SG. Consequences of transplant quality on chronic allograft nephropathy. Kidney Int Suppl. 2010;(119):S54-S58.

2. Erickson L, Wynn C, Pan F, et al. Microarray gene expression profiling of chronic allograft nephropathy in the rat kidney transplant model. Transpl Immunol. 2012;27(2-3):75-82.

3. Luo L, Sun Z, Luo G. Rapamycin is less fibrogenic than cyclosporin A as demonstrated in a rat model of chronic allograft nephropathy. J Surg Res. 2013;179(1):e255-e263.

4. Huang G, Wilson NA, Reese SR, Jacobson LM, Zhong W, Djamali A. Characterization of transfusion-elicited acute antibody-mediated rejection in a rat model of kidney transplantation. Am J Transplant. 2014;14(5):1061-1072.

5. Golby M, White HJ. The operation of orthotopic renal allografting in the pig and its complications. Br J Surg. 1971;58(4):287-288.

6. Collins DL, Christensen RM. Kidney transplantation in the dog: surgical technique. Can J Surg. 1966;9(3):308-315.

7. Mazzaferro V, Makowka L, Enrichens F, et al. A modified technique of orthotopic transplant of the kidney in rabbits. $J$ Invest Surg. 1989;2(3):293-303.

8. Fisher B, Lee S. Microvascular surgical techniques in research, with special reference to renal transplantation in rat. Surgery. 1965;58(5): 904-914.

9. Han WR, Murray-Segal LJ, Mottram PL. Modified technique for kidney transplantation in mice. Microsurgery. 1999;19(6):272-274.

10. Daniller A, Buchholz R, Chase RA. Renal transplantation in rats with the use of microsurgical techniques: a new method. Surgery. 1968;63(6):956-961.

11. Denecke C, Reutzel-Selke A, Sawitzki B, et al. Low-dose cyclosporine mediates donor hyporesponsiveness in a fully mismatched rat kidney transplant model. Transplant Immunol. 2012;26(4): 176-185.

12. Lee $\mathrm{S}$. An improved technique of renal transplantation in the rat. Surgery. 1967;61(5):771-773.

13. Frodin L. Renal transplantation in the rat. II. In vitro perfusion of rat kidneys before transplantation. Scand J Clin Lab Invest. 1975;35(5): 455-462.

14. Norlen BJ, Engberg A, Kallskog O, Wolgast M. Nephron function of the transplanted rat kidney. Kidney Int. 1978;14(1):10-20.

15. Oesterwitz H. [Orthotopic kidney transplantation in the rat with splintless end-to-end anastomosis of the ureter]. Z Urol Nephrol. 1982;75(6):377-386. German.

16. Churchill M, Kline R, Schwartz M, Bidani A, Churchill P. Kidney transplants in cyclosporine-treated Sprague-Dawley rats. Transplantation 1990;49(1):8-13.

17. Lopez-Neblina F, Toledo-Pereyra LH, Suzuki S. Ultrarapid orthotopic technique for renal transplantation in the rat. Microsurgery. 1994;15(4):274-278. 
18. Lauritzen CG. The sleeve anastomosis revisited. Ann Plast Surg. 1984;13(2):145-149.

19. Innocenti P, Bonetti G, Cotellese R, Gargano E, Materazzo D, Piattelli A. [Transplantation of the kidney in the rat. I. Problems of surgical technic]. Boll Soc Ital Biol Sper. 1979;55(20):2070-2075. Italian.

20. Bramis JP, Sloane CE, Schanzer H, Burrows L, Taub RN. Microsurgical renal transplantation techniques in small animals. Invest Urol. 1977;15(2):143-146.

21. Yin M, Booster MH, vd Bogaard AE, Kootstra G. A simple technique to harvest two kidneys from one donor rat for transplantation. Lab Anim. 1994;28(4):387-390.

22. D'Silva M, Gittes RF, Wolf $P$, et al. Rat kidney transplantation update with special reference to vesical calculi. Microsurgery. 1990;11(2): $169-176$.

23. Soots A, Lautenschlager I, Krogerus L, Saarinen O, Ahonen J. An experimental model of chronic renal allograft rejection in the rat using triple drug immunosuppression. Transplantation. 1998;65(1): $42-46$.

24. Diamond JR, Tilney NL, Frye J, et al. Progressive albuminuria and glomerulosclerosis in a rat model of chronic renal allograft rejection. Transplantation. 1992;54(4):710-716.

25. Wang M, Liu S, Ouyang N, Song E, Lutz J, Heemann U. Protective effects of FTY720 on chronic allograft nephropathy by reducing late lymphocytic infiltration. Kidney Int. 2004;66(3):1248-1256.

26. Heidenhain C, Reutzel-Selke A, Bachmann U, et al. The impact of immune-activating processes following transplantation on chronic allograft nephropathy. Kidney Int. 2003;64(3):1125-1133.

27. Schindler R, Tullius SG, TanriverY, et al. Hypertension increases expression of growth factors and MHC II in chronic allograft nephropathy. Kidney Int. 2003;63(6):2302-2308.

28. Heemann UW, Azuma H, Tullius SG, Mackenzie H, Brenner BM, Tilney NL. The contribution of reduced functioning mass to chronic kidney allograft dysfunction in rats. Transplantation. 1994;58(12): 1317-1322.

29. Herrero-Fresneda I, Torras J, Vidal A, Lloberas N, Cruzado JM, Grinyo JM. Reduction of postischemic immune inflammatory response: an effective strategy for attenuating chronic allograft nephropathy. Transplantation. 2005;79(2):165-173.

30. Yilmaz A, Yilmaz S, Kallio E, Rapola J, Hayry P. Evolution of glomerular basement membrane changes in chronic rejection. Transplantation. 1995;60(11):1314-1322.

31. Pascher A, Proesch S, Pratschke J, et al. Rat cytomegalovirus infection interferes with anti-CD4 mAb-(RIB 5/2) mediated tolerance and induces chronic allograft damage. Am J Transplant. 2006;6(9): 2035-2045.

32. Cao G, Lu Y, Gao R, et al. Comparison of cyclosporine versus mycophenolate mofetil on expression of fractalkine and CX3CR1 in chronic allograft nephropathy. Transplant Proc. 2006;38(7): 2234-2236.

33. Neto JS, Nakao A, Toyokawa H, et al. Low-dose carbon monoxide inhalation prevents development of chronic allograft nephropathy. Am J Physiol Renal Physiol. 2006;290(2):F324-F334.

34. White EHW, Mullen Y. Chronic kidney allograft reactions in rats. Transplantation. 1969;8(5):602-617.

35. Paul LC, Grothman GT, Benediktsson H, Davidoff A, Rozing J. Macrophage subpopulations in normal and transplanted heart and kidney tissues in the rat. Transplantation. 1992;53(1):157-162.

36. Paul LC, Muralidharan J, Muzaffar SA, et al. Antibodies against mesangial cells and their secretory products in chronic renal allograft rejection in the rat. Am J Pathol 1998;152(5):1209-1223.

37. Vass DG, Shrestha B, Haylor J, Hughes J, Marson L. Inflammatory lymphangiogenesis in a rat transplant model of interstitial fibrosis and tubular atrophy. Transplant Int. 2012;25(7):792-800.

38. de Heer E, Davidoff A, van der Wal A, van Geest M, Paul LC. Chronic renal allograft rejection in the rat. Transplantation-induced antibodies against basement membrane antigens. Lab Invest. 1994;70(4): 494-502.
39. Paul LC, Muralidharan J, Muzaffar SA, et al. Antibodies against mesangial cells and their secretory products in chronic renal allograft rejection in the rat. Am J Pathol. 1998;152(5):1209-1223.

40. Jain S, Furness PN, Nicholson ML. The role of transforming growth factor beta in chronic renal allograft nephropathy. Transplantation. 2000;69(9):1759-1766.

41. Berthier CC, Lods N, Joosten SA, et al. Differential regulation of metzincins in experimental chronic renal allograft rejection: potential markers and novel therapeutic targets. Kidney Int. 2006;69(2): 358-368.

42. Palin NK, Savikko J, Koskinen PK. Sirolimus inhibits lymphangiogenesis in rat renal allografts, a novel mechanism to prevent chronic kidney allograft injury. Transplant Int. 2013;26(2):195-205.

43. Grenz A, Baier D, Petroktistis F, et al. Theophylline improves early allograft function in rat kidney transplantation. J Pharmacol Exp Ther. 2006;317(2):473-479.

44. Hancock WW, Whitley WD, Baldwin WM 3rd, Tilney NL. Cells, cytokines, adhesion molecules, and humoral responses in a rat model of chronic renal allograft rejection. Transplant Proc. 1992;24(5): 2315-2316.

45. Azuma H, Chandraker A, Nadeau K, et al. Blockade of T-cell costimulation prevents development of experimental chronic renal allograft rejection. Proc Natl Acad Sci U S A. 1996;93(22): 12439-12444.

46. Laskowski IA, Pratschke J, Wilhelm MJ, et al. Anti-CD28 monoclonal antibody therapy prevents chronic rejection of renal allografts in rats. J Am Soc Nephrol. 2002;13(2):519-527.

47. Bedke J, Kiss E, Schaefer L, et al. Beneficial effects of CCR1 blockade on the progression of chronic renal allograft damage. Am J Transplant. 2007;7(3):527-537.

48. Song E, Zou H, Yao Y, et al. Early application of Met-RANTES ameliorates chronic allograft nephropathy. Kidney Int. 2002;61(2): 676-685.

49. Pilmore HL, Dittmer ID. Calcineurin inhibitor nephrotoxicity: reduction in dose results in marked improvement in renal function in patients with coexisting chronic allograft nephropathy. Clin Transplant. 2002;16(3): 191-195.

50. Noris M, Azzollini N, Pezzotta A, et al. Combined treatment with mycophenolate mofetil and an angiotensin II receptor antagonist fully protects from chronic rejection in a rat model of renal allograft. J Am Soc Nephrol. 2001;12(9):1937-1946.

51. Luo L, Sun Z, Wu W, Luo G. Mycophenolate mofetil and FK506 have different effects on kidney allograft fibrosis in rats that underwent chronic allograft nephropathy. BMC Nephrol. 2012;13:53.

52. Jolicoeur EM, Qi S, Xu D, Dumont L, Daloze P, Chen H. Combination therapy of mycophenolate mofetil and rapamycin in prevention of chronic renal allograft rejection in the rat. Transplantation. 2003;75(1): 54-59.

53. Viklicky O, Zou H, Muller V, Lacha J, Szabo A, Heemann U. SDZ-RAD prevents manifestation of chronic rejection in rat renal allografts. Transplantation. 2000;69(4):497-502.

54. Koch M, Mengel M, Poehnert D, Nashan B. Effects of everolimus on cellular and humoral immune processes leading to chronic allograft nephropathy in a rat model with sensitized recipients. Transplantation. 2007;83(4):498-505.

55. Ko HT, Yin JL, Wyburn K, et al. Sirolimus reduces vasculopathy but exacerbates proteinuria in association with inhibition of VEGF and VEGFR in a rat kidney model of chronic allograft dysfunction. Nephrol Dial Transplant. 2013;28(2):327-336.

56. Djamali A, Vidyasagar A, Adulla M, Hullett D, Reese S. Nox-2 is a modulator of fibrogenesis in kidney allografts. Am J Transplant. 2009;9(1):74-82.

57. Albrecht EW, van Goor H, Smit-van Oosten A, Stegeman CA. Long-term dietary L-arginine supplementation attenuates proteinuria and focal glomerulosclerosis in experimental chronic renal transplant failure. Nitric Oxide. 2003;8(1):53-58.

58. Gottmann U, Oltersdorf J, Schaub M, et al. Oxidative stress in chronic renal allograft nephropathy in rats: effects of long-term treatment with carvedilol, BM 91.0228, or alpha-tocopherol. J Cardiovasc Pharmacol. $2003 ; 42(3): 442-450$. 
59. Djamali A, Vidyasagar A, Yagci G, Huang LJ, Reese S. Mycophenolic acid may delay allograft fibrosis by inhibiting transforming growth factor-beta1-induced activation of Nox-2 through the nuclear factor-kappaB pathway. Transplantation. 2010;90(4):387-393.

60. Amuchastegui SC, Azzollini N, Mister M, Pezzotta A, Perico N, Remuzzi G. Chronic allograft nephropathy in the rat is improved by angiotensin II receptor blockade but not by calcium channel antagonism. J Am Soc Nephrol. 1998;9(10):1948-1955.

61. Noris M, Mister M, Pezzotta A, et al. ACE inhibition limits chronic injury of kidney transplant even with treatment started when lesions are established. Kidney Int. 2003;64(6):2253-2261.

62. Ji P, Si MS, Podnos Y, Chow H, Steward E, Imagawa DK. Prevention of chronic rejection by pravastatin in a rat kidney transplant model. Transplantation. 2002;74(6):821-827.

63. Lahmer T, Hermans R, Schmaderer C, et al. Mineralocorticoid receptor antagonism and aldosterone synthesis inhibition do not improve glomerulosclerosis and renal interstitial fibrosis in a model of chronic kidney allograft injury. Kidney Blood Press Res. 2012;35(6): 561-567.

64. Inkinen K, Soots A, Krogerus L, Bruggeman C, Ahonen J, Lautenschlager I. Cytomegalovirus increases collagen synthesis in chronic rejection in the rat. Nephrol Dial Transplant. 2002;17(5): $772-779$.

65. Lautenschlager I, Soots A, Krogerus L, et al. CMV increases inflammation and accelerates chronic rejection in rat kidney allografts. Transplant Proc. 1997;29(1-2):802-803.

66. Soots A, Krogerus L, Lautenschlager I, Ahonen J. The effect of sodium nitroprusside on the chronic allograft damage in a rat model of renal transplantation. Transplant Proc. 2001;33(1-2):853.

67. Yilmaz S, Yilmaz A, Hayry P. Chronic renal allograft rejection can be predicted by area under the serum creatinine versus time curve (AUCCr). Kidney Int. 1995;48(1):251-258.

68. Yilmaz S, Hayry P. The impact of acute episodes of rejection on the generation of chronic rejection in rat renal allografts. Transplantation. 1993;56(5):1153-1156.
69. Savikko J, Rintala JM, Rintala SE, Koskinen PK, von Willebrand E. Early short-term imatinib treatment is sufficient to prevent the development of chronic allograft nephropathy. Nephrol Dial Transplant. 2011;26(9):3026-3032.

70. Rintala JM, Savikko J, Rintala SE, von Willebrand E. FK778 ameliorates post-transplant expression of fibrogenic growth factors and development of chronic rejection changes in rat kidney allografts. Nephrol Dial Transplant. 2008;23(11):3446-3455.

71. Martins PN, Reutzel-Selke A, Jurisch A, et al. Induction of carbon monoxide in donor animals prior to organ procurement reduces graft immunogenicity and inhibits chronic allograft dysfunction. Transplantation. 2006;82(7):938-944.

72. Grau V, Fuchs-Moll G, Wilker S, Weimer R, Padberg W. Proliferation of CD8-positive T cells in blood vessels of rat renal allografts. Am J Transplant. 2011;11(9):1979-1985.

73. Teng D, Lu Y, Gao R, et al. Conversion from cyclosporine to mycophenolate mofetil improves expression of A20 in the rat kidney allografts undergoing chronic rejection. Transplant Proc. 2006;38(7): 2164-2167.

74. Teng D, Lu Y, Gao R, et al. Comparison of rapamycin versus FK506 on expression of cytoprotective genes in the rat kidney allografts undergoing chronic allograft nephropathy. Transplant Proc. 2006;38(7):2172-2175.

75. Cardinal JS, Zhan J, Wang Y, et al. Oral hydrogen water prevents chronic allograft nephropathy in rats. Kidney Int. 2010;77(2):101-109.

76. Solini S, Aiello S, Cassis P, et al. Prolonged cold ischemia accelerates cellular and humoral chronic rejection in a rat model of kidney allotransplantation. Transplant Int. 2012;25(3):347-356.

77. Benigni A, Tomasoni S, Turka LA, et al. Adeno-associated virusmediated CTLA4Ig gene transfer protects MHC-mismatched renal allografts from chronic rejection. J Am Soc Nephrol. 2006;17(6): 1665-1672.

78. Waaga-Gasser AM, Grimm MR, Lutz J, et al. Regulatory allospecific $\mathrm{T}$ cell clones abrogate chronic allograft rejection. J Am Soc Nephrol. 2009;20(4):820-830.

\section{Publish your work in this journal}

The International Journal of Nephrology and Renovascular Disease is an international, peer-reviewed open-access journal focusing on the pathophysiology of the kidney and vascular supply. Epidemiology, screening, diagnosis, and treatment interventions are covered as well as basic science, biochemical and immunological studies. The journal welcomes original research, clinical studies, reviews \& evaluations, expert opinion and commentary, case reports and extended reports. The manuscript management system is completely online and includes a very quick and fair peerreview system, which is all easy to use. Visit http://www.dovepress.com/ testimonials.php to read real quotes from published authors. 